\title{
A Review of Low-Carbon Transformation and Energy Innovation Issues in China
}

\author{
Liexun Yang ${ }^{1}$, Peng Zhou ${ }^{2}$ and Ning Zhang ${ }^{1,3, *}$ \\ 1 Department of Management Sciences, the National Natural Science Foundation of China, \\ Beijing 100085, China; yanglx@nsfc.gov.cn \\ 2 College of Economics and Management, Nanjing University of Aeronautics and Astronautics, \\ 29 Jiangjun Avenue, Nanjing 211106, China; cemzp@nuaa.edu.cn \\ 3 College of Economics, Jinan University, No. 601, West of Huangpu Avenue, Tianhe District, \\ Guangzhou 510632, China \\ * Correspondence: glsc@nsfc.gov.cn or zhangn@jnu.edu.cn; Tel.: +86-20-85-220-174; Fax: +86-20-85-223-790
}

Received: 9 July 2017; Accepted: 11 July 2017; Published: 15 July 2017

\begin{abstract}
Scale-oriented economic development in China has given rise to problems associated with high energy consumption and severe environmental pollution. Thus, the 7th China Annual Conference of Energy Economics and Management provides a platform for presenting ongoing research activities in order to exchange research ideas in the area of low-carbon economics and sustainable development for China. We thank Sustainability for providing this timely special issue. This editorial highlights the contents and methodologies of this conference special issue, presenting several important issues in energy economics and management.
\end{abstract}

Keywords: low-carbon development; environmental policy; innovation; 7th-annual-conf-EEM

\section{Background of the Special Issue}

Along with rapid economic growth, environmental issues have become increasingly serious due to excessive energy usage and carbon emissions [1]. To enhance environmental performance, low-carbon transformation and energy innovation in energy economics and management are attracting increasing attention from both scholars and policymakers. Against this background, the 7th China Annual Conference of Energy Economics and Management with the theme of "Low-Carbon Transformation and Energy Innovation" was held in Nanjing, China, 14-16 October 2016. This conference was co-hosted by the Department of Management Science, National Natural Science Foundation of China (NSFC), the Chinese Society of Energy Economics and Management (under SCOPE), and Nanjing University of Aeronautics and Astronautics. Nearly 400 experts and scholars from more than 100 universities and research institutes in the field of energy economics, policy and management took part in the conference.

This conference is one of the leading conferences in China for presenting novel and fundamental advances in energy economics and management for policy decision-making. The scope of this special issue encompasses topics related to energy economics and management, low-carbon management, and sustainability in China, at both the macro- and micro-levels, as presented at the 7th Annual Conference of Energy Economics and Management. Certainly, this conference is benefiting from Sustainability, which provides opportunities for delegates to exchange new working papers and application experiences, face-to-face, in order to establish research and collaborative relationships. From this conference, 10 journal papers focusing on issues of "Energy Economics and Management" were selected and published in this special issue, through the standard peer review process (http://www.mdpi.com/journal/sustainability/specialissues/conferenceEEM). 
The 7th Annual Conference of Energy Economics and Management was the cornerstone of a new platform for academic networking to present ongoing research activities and exchange research ideas in the area of energy economics and management. This conference has made a positive contribution to the overall level of scholarship in the field and inspired young researchers in energy economics and management.

\section{Important Issues for China's Energy Economics and Management}

Since the GDP and its growth speed were deemed the two most important measures on economic development for China in the early 1980s, both the central government and local government in China exerted themselves to compete for various resources, in order to expand their GDP for the possible promotion of their own. Meanwhile, abiding by the philosophy of "supreme economic, development first", almost every province in China has implemented a consistent policy of "first pollution, then treatment", and the mode of "high input, high output and high emissions" across all industries, especially in the southeast coastal provinces. Therefore, China is facing severe environmental problems such as air pollution, sewage pollution, and climate challenges, resulting from the country's rapid economic growth.

Indeed, to strike a balance between environment protection and economic development, more attention is being given to sustainability, putting pressure on the Chinese government to introduce scientific and feasible policies to balance economic development and environmental problems. Several papers examine the effectiveness of the environmental policies pushed by China's government. One study presented in this issue takes industrial development as an example. It first introduces a non-cooperative game to characterize the leader-follower relationship between the industrial production sub-system and pollution treatment sub-system in each province, and then proposes a novel two-stage SBM-DEA model to evaluate the provincial efficiency of both industrial production and pollutant treatment with the data from 2003-2012, based on which the effectiveness of the environmental protection policies of the central government is assessed [1]. Results show that the proposed novel two-stage SBM-DEA model can describe the environmental efficiency more precisely than traditional DEA models. Further, the efficiencies of the industrial production sub-system and the pollution treatment sub-system at the provincial level are both relatively low. Specifically, the efficiency of industrial production is not only lower than the pollution treatment efficiency, but it is falling in general, especially in the eastern area. However, in the central and western areas, the efficiency of industrial production remains relatively stable, and the pollution treatment efficiency is rising steadily. The technology gap between the central/western areas and the eastern area is narrowing, particularly in pollution treatment technology [1].

As stated above, air pollution has become a serious challenge in China. Motor vehicles are one of the main sources of air pollution and the Chinese government has implemented numerous green policies to mitigate harmful emissions from the road transport sector. Moreover, both policymakers and researchers are unclear on whether these policies are effective in the short and long term. Therefore, one study proposes a new concept of "pollution rebound effect" (PRE) to estimate the effectiveness of green traffic policies. The empirical results indicate that direct PRE did not exist in the road passenger transport sector for the whole of China during 1986-2014, and implies that improving the fuel efficiency of vehicles is a useful policy option for decreasing transport energy use, resulting in the reduction of harmful gas emissions [2].

In addition to the issues surrounding the effectiveness of environmental policy, the impact of low-carbon innovation on $\mathrm{CO}_{2}$ emissions has attracted much attention from scholars as well. For example, Yan et al. [3] investigate the impact of low-carbon innovation (LCI) and its heterogeneous components on $\mathrm{CO}_{2}$ emissions. The empirical results based on an EKC framework showed that the LCI is not a significant factor in $\mathrm{CO}_{2}$ emissions. However, as the effect of its heterogeneous components on $\mathrm{CO}_{2}$ emissions was analyzed, a significantly negative effect of clean innovation was found, while the 
effect of gray innovation is not clear. Heterogeneous impacts within low-carbon technology provide an explanation for the non-significant impact of low-carbon innovation [3].

There are also debates about the relationship between trade liberalization and carbon emissions. Based on different perspectives, several studies focus on the carbon embodied in import and export trade, while others explore the impact of FDI on carbon emissions. To resolve the theoretical ambiguity, Ding et al. [4] turn to an empirical analysis of the pattern of foreign direct investment, and conduct thorough research into the $\mathrm{CO}_{2}$ emissions problem caused by China's OFDI. Thirty-four host countries were selected as the study sample, and their $\mathrm{CO}_{2}$ emissions as caused by China's OFDI were calculated using the input-output model with non-competitive imports, the data of China's OFDI flows, and their own energy consumption and $\mathrm{CO}_{2}$ emissions from 2000 to 2011. The results showed that China's OFDI could achieve the aim of reducing global carbon emissions with reasonable industry and location selection [4].

Among greenhouse gas (GHG) emissions, $\mathrm{CO}_{2}$ presents the most serious concern for sustainable development [5]. GHG benchmarking for allocation serves as a reward for early actions in mitigating GHG emissions by using more advanced technologies. Recognizing the need for action, China Hubei introduced the carbon emission trading pilot in 2014 to reduce GHG emissions, and the cement industry was recognized as a major contributor to the GHG emissions in Hubei [6]. For the feasibility of this project, the empirical study established a general benchmarking framework by describing and calculating the marginal abatement cost curve (MACC) and marginal revenue, and then comparing the different GHG benchmarking approaches for the cement industry in the Hubei Emission Trading Pilot (Hubei ETS) case. The results of the three different approaches used in the research, the Waxman-Markey approach, the EU ETS approach, and the California ETS approach, showed: (1) the Waxman-Markey benchmark is too loose to apply in Hubei as it provides little incentive for companies to mitigate; (2) the EU ETS benchmark approach fits the current cement industry in Hubei ETS; and (3) the GHG benchmarking standard in the California Cap-and-Trade Program is the most stringent standard and drives the direction of the future development for the Hubei ETS [6].

While the cement industry is the major contributor to the GHG emissions, the lithium-ion battery industry also leaves a considerable burden on the environment and generates GHG emissions. Hao et al. [7] estimates the GHG emissions from the production of lithium-ion batteries in China by establishing a life cycle assessment framework, finding a 30\% increase in GHG emissions from vehicle production compared with conventional vehicles. They recommend that great efforts be made to reduce the GHG emissions from battery production in China, with improving the production of cathodes as the essential measure [7].

For sustainable development, wind energy has been considered as one of the most important kinds of clean energy that results in saving fossil fuels and reducing greenhouse gas emissions. Because wind power has strong randomness and instability, and it cannot be controlled by operators in the same way as other generation resources. Therefore, improving the accuracy of short-term wind speed forecasting is crucial for the operation of wind power plants [8]. Zhang et al. [8] propose a new hybrid method combining ensemble empirical mode decomposition (EEMD), adaptive neural network based fuzzy inference system (ANFIS), and seasonal auto-regression integrated moving average (SARIMA) for short-term wind speed forecasting. The empirical results show that the proposed method can provide more accurate and effective prediction results [8].

As oil prices receive increasing attention from the public, researchers prefer to study the dynamic behavior of heating oil spot and futures prices, especially for American heating oil spot and futures price fluctuation networks due to America's influence on global markets [9]. Chen et al. [9] processed the spot and future pricing of American heating oil using coarse grain processing technology based on the complex network view, and found that the cumulative time of new nodes appearing in either spot or futures price network is not random, but exhibits the growth trend of straight line. Meanwhile, the power law distributions of spot and futures price fluctuations in different periods present regularity and complexity. Moreover, these prices are strongly correlated in periods of stable 
fluctuation, but are weakly correlated in periods of sharp fluctuation. The study presents the time distribution characteristics of important modes in the networks and the evolution results of the topological properties [9], while in most previous studies of international oil price transmission, the long-run relationship and short-run dynamics of gasoline and diesel price changes in China are tested [10]. It was found that China's gasoline and diesel prices increase quickly when international crude oil prices rise, but decrease slowly when international crude oil prices decline. Furthermore, both increases and decreases in the growth rate of international crude oil prices have a greater effect on China's diesel prices than on gasoline prices [10].

The above studies represent macro-level research based on macroeconomic statistics data. However, one micro-level paper presents a detailed analysis of fuel choice and usage behavior of different end-use activities in rural residential energy consumption based on 717 observation surveys in two counties of northern China in Shandong and Hebei provinces in 2016 [11]. This paper describes the characteristics of rural energy consumption and the detailed usage behaviors by remedying the data limitations of previous studies through a detailed questionnaire design, offering in-depth investigations of the different fuel choices of end-use activities, which can provide a reference for decision-making [11].

\section{Methodologies of Energy Economics and Management}

Most papers in this special issue show great interest in the effectiveness of environmental policy $[1,2]$ and pollution emissions $[3,4,6,7]$. Some of these studies use a conventional regression method to analyze the impacts of green transport policy [2] and low-carbon innovation [3], but the downside of this method is that conventional regressions cannot test and analyze the efficiency of inter-regional industrial systems, or specifically to identify the reasons for the ineffectiveness of a particular industrial system. Therefore, the environmental efficiency evaluation based on DEA has been widely favored by environmental economists, due to its unique advantages in the efficiency evaluation for homogeneous decision-making units (DMUs) with multiple inputs and outputs [12]. However, the traditional DEA models are still limited to the radial method, in which all input variables can only be contracted proportionally or all output variables can only be expanded proportionally. In this case, a novel slack-based measure data envelopment analysis (SBM-DEA) model with a non-cooperative game was proposed to evaluate the environment efficiency of both industrial production and pollutant treatment sub-systems [1]. Further, input-output analysis is also an effective approach for calculating $\mathrm{CO}_{2}$ emissions from China's OFDI because the input-output model with non-competitive imports represents monetary transactions between supply chains in mathematical form, and the input-output model can incorporate either the competitive or the non-competitive imports assumption [4].

For greenhouse gas (GHG) emissions, one paper establishes a life cycle assessment framework and estimates GHG emissions from the production of lithium-ion batteries in China [7]; another combines the Waxman-Markey approach, the EU ETS approach, and California ETS approach to established a general benchmarking framework by describing and calculating the marginal abatement cost curve (MACC) and marginal revenue and then comparing the different GHG benchmarking approaches for the cement industry in the Hubei Emission Trading Pilot (Hubei ETS) case [6]. The best GHG emission benchmarking approach for the cement industry can be determined by comparing the results of three approaches [6]. Another paper proposes a hybrid method that combines ensemble empirical mode decomposition (EEMD), adaptive neural network based fuzzy inference system (ANFIS), and the seasonal auto-regression integrated moving average (SARIMA) for short-term wind speed forecasting [8]. These empirical studies use a variety of approaches, indicating that combining different methods can provide more accurate and effective prediction results.

The authors also use the linear regression or linear transformation of multivariant variables. As mentioned earlier, the impacts of green transport policy [2] and low-carbon innovation [3] were analyzed by using the conventional regression of the log linearization of the model. Meanwhile, in order to examine whether China's gasoline and diesel prices adjust asymmetrically to international 
crude oil price changes, a linear regression was used to analyze its long-run relationship and an error-correction methodology was introduced to examine the short-run dynamics of gasoline or diesel price changes in response to changes in international oil prices [10].

Descriptive analysis is also used. Though the descriptive analysis does not use empirical models, it is able to analyze issues clearly, especially with the survey data from farmers, due to its authenticity and engagement. Wu et al. [11] conducted a detailed analysis of fuel choice and usage behavior of different end-use activities in rural residential energy consumption by using micro-survey data in two counties of Shandong and Hebei province. This study can provide a reference for decision-making.

Finally, previous studies of heating oil price fluctuations often use the traditional mathematical analysis method, which cannot effectively reflect the evolution characteristics of topological dynamics changing with time. Chen et al. [10] innovatively propose methods to analyze the dynamic evolutionary behavior of American heating oil spot and futures price fluctuation networks, namely the source and coarse graining process of data, period division process, the construction of complex network models, and some concepts of network topological properties [10].

Because of the interdisciplinary nature of energy economics and management, diverse approaches could, and should, be imported and used for a better understanding of multivariate complexity, as well as for the generation of more systematic implications and suggestions [13-16].

\section{Conclusions}

The articles in this special issue offer important insights to scholars, policymakers, and entrepreneurs about emerging low-carbon transformation and energy innovation issues. The research findings offer guidance to practitioners to help them to better study the increasingly serious environmental problems. However, the existing system of basic research, clean energy investment, regulatory frameworks, and subsidies fails to sufficiently mobilize investment for truly transformative energy solutions for the future. From the perspective of global leaders, the existing low-carbon technology system and the degree of energy innovation are unsatisfactory in terms of their capability for climate change mitigation. People are finding new impetus to investigate the effects of low-carbon innovation and its components on $\mathrm{CO}_{2}$ emission, which is helpful for policy-making for a low-carbon future. Hence, these issues of energy economics and management with the topic of "Low-Carbon Transformation and Energy Innovation" have captured the attention of the participants at the 7th China Annual Conference of Energy Economics and Management.

In sum, the research articles in this special issue contain broadly useful perspectives and evidence for energy economics and management based on empirical analysis or descriptive analysis. Energy and environmental issues arise in a range of important situations, including environmental policies [1,2], $\mathrm{CO}_{2}$ emissions [3,4], GHG emissions [6,7], wind speed prediction [8], oil prices [9,10], and residential fuel choice [11]. One approach potentially leads to describing just one facet of a more complex issue. Undoubtedly, the papers in this special issue make important contributions to furthering our understanding of key attributes of the changes now underway. While the tail has been found, a fair bit of the elephant remains a mystery! We still hope that the findings in this special issue will stimulate future research in the interesting and important research area of energy economics and management.

Acknowledgments: We thank the Editors of Sustainability for providing this special issue. Ning Zhang gratefully acknowledge the financial support from the National Natural Science Foundation of China $(41461118,71603102)$, National Social Science Foundation of China (14ZDB144; 15ZDA054), and Research Center on Low-carbon Economy for Guangzhou Region.

Author Contributions: All authors made equal contributions to the work in this editorial paper.

Conflicts of Interest: The authors declare no conflict of interest. 


\section{References}

1. Xia, Q.; Li, M.; Wu, H.; Lu, Z. Does the Central Government's Environmental Policy Work? Evidence from the Provincial-Level Environment Efficiency in China. Sustainability 2016, 8, 1241. [CrossRef]

2. Qiu, L.; He, L. Are Chinese Green Transport Policies Effective? A New Perspective from Direct Pollution Rebound Effect, and Empirical Evidence from the Road Transport Sector. Sustainability 2017, 9, 429. [CrossRef]

3. Yan, Z.; Yi, L.; Du, K.; Yang, Z. Impacts of Low-Carbon Innovation and Its Heterogeneous Components on $\mathrm{CO}_{2}$ Emissions. Sustainability 2017, 9, 548. [CrossRef]

4. Ding, T.; Ning, Y.; Zhang, Y. The Contribution of China's Outward Foreign Direct Investment (OFDI) to the Reduction of Global $\mathrm{CO}_{2}$ Emissions. Sustainability 2017, 9, 741. [CrossRef]

5. Choi, Y.; Song, M.; Myeong, S. Introduction to the Special Issue on the Sustainable Asia Conference 2015. Sustainability 2016, 8, 266. [CrossRef]

6. Dai, F.; Xiong, L.; Ma, D. How to Set the Allowance Benchmarking for Cement Industry in China's Carbon Market: Marginal Analysis and the Case of the Hubei Emission Trading Pilot. Sustainability 2017, 9, 322. [CrossRef]

7. Hao, H.; Mu, Z.; Jiang, S.; Liu, Z.; Zhao, F. GHG Emissions from the Production of Lithium-Ion Batteries for Electric Vehicles in China. Sustainability 2017, 9, 504. [CrossRef]

8. Zhang, J.; Wei, Y.; Tan, Z.; Ke, W.; Tian, W. A Hybrid Method for Short-Term Wind Speed Forecasting. Sustainability 2017, 9, 596. [CrossRef]

9. Chen, H.; Tian, L.; Wang, M.; Zhen, Z. Analysis of the Dynamic Evolutionary Behavior of American Heating Oil Spot and Futures Price Fluctuation Networks. Sustainability 2017, 9, 574. [CrossRef]

10. Chen, Y.; Huang, G.; Ma, L. Rockets and Feathers: The Asymmetric Effect between China's Refined Oil Prices and International Crude Oil Prices. Sustainability 2017, 9, 381. [CrossRef]

11. Wu, J.; Hou, B.; Ke, R.; Du, Y.; Wang, C.; Li, X.; Cai, J.; Chen, T.; Teng, M.; Liu, J.; et al. Residential Fuel Choice in Rural Areas: Field Research of Two Counties of North China. Sustainability 2017, 9, 609. [CrossRef]

12. Zhang, N.; Wang, B. Toward a Sustainable Low-Carbon China: A Review of the Special Issue of "Energy Economics and Management". Sustainability 2016, 8, 823. [CrossRef]

13. Choi, Y.; Zhang, N. Introduction to the Special Issue on "The Sustainable Asia Conference 2014". Sustainability 2015, 7, 1595-1602. [CrossRef]

14. Zhang, N.; Chen, Z. Sustainability characteristics of China's Poyang Lake Eco-Economics Zone in the big data environment. J. Clean. Prod. 2017, 142, 642-653. [CrossRef]

15. Zhang, N.; Wang, B.; Chen, Z. Carbon emission reductions and technology gaps in the world's factory, 1990-2012. Energy Policy 2016, 91, 28-37. [CrossRef]

16. Zhang, N.; Wang, B.; Liu, Z. Carbon emissions dynamics, efficiency gains, and technological innovation in China's industrial sectors. Energy 2016, 99, 10-19. [CrossRef]

(C) 2017 by the authors. Licensee MDPI, Basel, Switzerland. This article is an open access article distributed under the terms and conditions of the Creative Commons Attribution (CC BY) license (http://creativecommons.org/licenses/by/4.0/). 